[Manuscript version. Final paper published in 2014 edition of Philosophical Issues (supplement to Noûs), edited by Jesper Kallestrup and Duncan Pritchard.]

\title{
Empiricism for cyborgs
}

\author{
Adam Toon \\ University of Exeter
}

\begin{abstract}
One important debate between scientific realists and constructive empiricists concerns whether we observe things using instruments. This paper offers a new perspective on the debate over instruments by looking to recent discussion in philosophy of mind and cognitive science. Realists often speak of instruments as 'extensions' to our senses. I ask whether the realist may strengthen her view by drawing on the extended mind thesis. Proponents of the extended mind thesis claim that cognitive processes can sometimes extend beyond our brains and bodies into the environment. I suggest that the extended mind thesis offers a way to make sense of realists' talk of instruments as extensions to the senses and that it provides the realist with a new argument against the constructive empiricist view of instruments.
\end{abstract}

\section{Keywords}

Scientific realism - Constructive empiricism - Instruments - Microscopes - Extended mind thesis - Bas van Fraassen - Andy Clark 


\section{Introduction}

One important debate between scientific realists and constructive empiricists concerns whether we observe things using instruments. Scientific realists argue that we do and that the development of scientific instruments has enabled us to observe new realms of phenomena previously beyond the reach of our senses. According to the realist, for example, the invention of the microscope means that we can now see cells and microbes. In contrast, constructive empiricists argue that the use of instruments does not count as observation. The development of instruments has created new phenomena that we can observe with the naked eye and which our theories must accommodate, such as the tracks in a bubble chamber or the images produced by an electron microscope or CAT scanner, but it has not widened the reach of our senses. Observation remains limited to the use of our unaided senses and, as a result, for the constructive empiricist, so too does scientific knowledge.

Realists often speak of instruments as 'extensions' to our normal cognitive capacities. For example, in his book on instruments and computational science, revealingly entitled Extending Ourselves, Paul Humphreys argues that

[o]ne of science's most important epistemological and metaphysical achievements has been its success in enlarging the range of our natural human abilities (2004, pp. 3-4)

In Humphreys' view, the extension of our natural abilities through instruments has profound implications for epistemology and philosophy of science. In fact, 'in extending ourselves, scientific epistemology is no longer human epistemology' (2004, p. 8).

In this paper, I will ask whether the realist may flesh out her view of instruments by drawing on the extended mind thesis (Clark and Chalmers, 1998). Proponents of the extended mind thesis claim that cognitive processes, including perceptual processes, can sometimes extend beyond our brains and bodies into the environment. Although some 
have begun to explore the consequences of the extended mind thesis for epistemology

(e.g. Clark et al., 2012; Pritchard, 2010; Vaesen, 2011), its implications for the philosophy of science have yet to be properly explored (although see Estany and Sturm, 2014). I will suggest that the extended mind thesis offers a way to make sense of realists' talk of instruments as extensions to the senses and that it provides the realist with a new argument against the constructive empiricist view of instruments. One defender of the extended mind thesis describes humans as 'natural born cyborgs', ever-ready to incorporate external devices into their cognitive processes (Clark, 2003). In this paper, I consider the consequences of this vision of humanity for the debate over scientific realism. The result, I suggest, is an empiricism for cyborgs: a position consistent with the constructive empiricist's core claim, that we should restrict our belief to observable phenomena, but in which the limits of observation far outstrip what can be seen with the naked eye.

The structure of the paper is as follows. First, in Section 2, I briefly review the debate over instruments between realists and constructive empiricists. In Sections 3 and 4, I introduce the extended mind thesis and show how realists might use it to offer a new argument against the constructive empiricist view of instruments, which I will call the extended perception argument. In Section 5, I consider how this argument differs from well-known realist arguments put forward by Grover Maxwell and Paul Churchland. Finally, in Section 6, I consider some of the strengths of the extended perception argument compared to other realist strategies, as well as some likely objections. We will also see how the debate between realists and constructive empiricists might turn out to depend upon our conception of persons and the bounds of the epistemic community.

\section{Empiricists and realists on instruments}

Scientific realists and constructive empiricists differ, first, in their overall picture of the aims of scientific inquiry and, second, in their account of the role of instruments within that inquiry. According to the constructive empiricist, 
[s]cience aims to give us theories which are empirically adequate; and acceptance of a theory involves a belief only that it is empirically adequate (Van Fraassen, 1980, p. 12)

A theory is empirically adequate providing that what it says about the observable phenomena is true, where something counts as observable if there are conditions under which we can observe it. Thus, the moons of Jupiter are observable, since if we were sufficiently close we would be able to observe them (Van Fraassen, 1980, p. 16). Van Fraassen is clear that by 'observation' he means unaided perception, that is, perception without instruments (e.g. 1980, pp. 13-19; 2008, p. 93). For the constructive empiricist, then, cells or microbes do not count as observable, even though scientists might talk about 'seeing' such things through a microscope. Rather than thinking of microscopes as windows on the invisible world, van Fraassen suggests that we understand them as machines for generating new observable phenomena (2001; 2008, Chapter 4). Van Fraassen draws a parallel with rainbows. Rainbows are public hallucinations: we may all stand together and look at a rainbow in the sky, point to it or even photograph it, but there is, of course, no material object that we are seeing. Similarly, van Fraassen suggests, we may understand the microscope as a machine for generating a new, public hallucination, suspending our judgment regarding whether the objects that we seem to see are real or not (2008, Chapter 4).

In contrast to the constructive empiricist, scientific realists deny that scientific knowledge is limited only to observable phenomena. For the realist, science aims to give us theories that are true (or at least approximately true), not merely empirically adequate. Accepting a theory involves believing it to be true (or approximately true). Unlike the constructive empiricist, then, the realist argues that we should believe what our (mature, successful) scientific theories say about all phenomena, whether observable or not. Moreover, many realists deny that observation is limited to the unaided senses. Instead, they argue, scientific instruments allow us to observe new phenomena that lie beyond the reach of our unaided senses. According to this view, microscopes are windows on the invisible world (albeit perhaps imperfect ones), which allow us to see new objects, like cells or microbes 
(Alspector-Kelly, 2004; Hacking, 1983; Teller, 2001; for a recent critical discussion, see Kusch, 2013). As a result, the realist argues, the boundaries of the observable are not fixed once and for all by the limitations of the human eye. Instead, those boundaries are constantly expanding as new instruments are developed and put to use in scientific inquiry (Alspector-Kelly, 2004; Humphreys, 2004).

We may thus distinguish two different issues dividing the realist and constructive empiricist. The first issue concerns whether we should limit our belief to what our theories say about the observable phenomena only, or whether we should also believe what they tell us about the unobservable. The second issue concerns whether observation is limited to use of the unaided senses, or whether use of instruments may also count as observation. Thus, while the first issue is about the epistemic significance of observability, the second concerns its scope. In what follows, we will focus on this second question. As we will see, the extended mind thesis allows the realist to argue that the use of instruments can sometimes count as an act of observation. But we should note immediately that, even if this view of instruments is correct, this will not settle the debate over the first issue. That is, even if the realist is correct to say that instruments may sometimes expand the boundaries of the observable, to include objects previously beyond the reach of our senses, the empiricist might still urge us to believe what our theories say only within those (newly expanded) boundaries and no further (on this point see, for example, van Fraassen 2001, pp. 162-163).

\section{The extended mind thesis}

As we have seen, for the constructive empiricist, the limits of observability are the limits of our senses. Furthermore, according to van Fraassen, the limits of our senses are to be discovered by science itself:

The human organism is, from the point of view of physics, a certain kind of measuring apparatus. As such, it has certain inherent limitations - which will be described in detail in the final physics and biology. It is these 
limitations to which the 'able' in 'observable' refers - our limitations qua human beings (Van Fraassen, 1980, p. 17).

Although van Fraassen refers only to physics and biology, presumably perceptual psychology will also play an important role here (Alspector-Kelly, 2004). Amongst contemporary theories of perception, and theories of cognition more broadly, we find a set of movements that emphasize the importance of interactions between the brain, body and environment, such as situated cognition, embodied cognition and distributed cognition (for an overview, see Robbins and Aydede, 2009). In light of these developments, a number of philosophers of mind and cognitive science have been led to endorse the extended mind thesis. Although most often associated with Clark and Chalmers (1998), similar views have also been defended by many others, including Richard Menary (2007), Mark Rowlands (1999), Mike Wheeler (2005) and Robert Wilson (2004).

Although we might normally think of cognition as something that happens in the brain, the extended mind thesis claims that cognitive processes can sometimes extend outside our brains, and even outside our bodies. To motivate this idea, Clark and Chalmers (1998) offer us the famous example of Otto and Inga. When Inga hears of an exhibition at the Museum of Modern Art she recalls that the museum is on $53^{\text {rd }}$ Street, and sets off. Otto is an Alzheimer's patient who carries a notebook with him wherever he goes to record useful information. When Otto hears of the exhibition, he looks up the information in his notebook, and sets off. Clark and Chalmers argue that Otto's notebook plays a similar functional role in Otto's life as Inga's biological memory does in hers. As a result, they claim, the notebook is part of Otto's cognitive processes. Otto believes that the exhibition is on $53^{\text {rd }}$ Street, even before he looks at his notebook, just as Inga believes this even before consulting her memory.

Key to Clark and Chalmers' argument is what has become known as the parity principle:

If, as we confront some task, a part of the world functions as a process which, were it done in the head, we would have no hesitation in recognizing 
as part of the cognitive process, then that part of the world is (so we claim) part of the cognitive process (1998, p. 8).

There has been considerable debate in the literature about the best way to understand the parity principle. Often, it is understood as claiming that an external process only counts as part of the cognitive process only if it displays a close similarity to an existing internal process, like biological memory. Critics have then proceeded to point out a number of fine-grained differences between Otto's notebook and internal, biological memory (e.g. Adams and Aizawa 2001, Rupert 2004). For example, biological memory exhibits generation effects, meaning that people remember things better if they have formulated a mnemonic themselves, rather than having one given to them. And yet it seems that such effects will be absent from Otto's notebook. However, Clark is keen to stress that this reading of the parity principle is too restrictive (e.g. Clark, 2008, p. 114). After all, it seems that aliens or other beings might differ from us in all sorts of fine-grained physical and psychological ways, and yet still have mental states. For example, we surely wouldn't deny that a Martian had memories simply because it didn't exhibit generation effects (Sprevak, 2009).

Rather than providing a means of distinguishing cognitive and non-cognitive processes, the parity principle is intended to act as a heuristic device, encouraging us to abandon our prejudices regarding where cognition is located and form judgments about what counts as cognition behind what Clark calls a "veil of metabolic ignorance" (2008, p. 114). At this point, however, we might ask: what does determine whether something is a cognitive process or not? Here, opinion is divided. Some supporters of the extended mind thesis, like Mike Wheeler, argue that what is needed is a mark of the cognitive, that is, "a scientifically informed, theory-loaded, locationally uncommitted account of the cognitive" (Wheeler, 2011, p. 419). Others, like Clark himself, appeal instead to our intuitive sense of what counts as a cognitive process. For the purposes of this paper, I will follow Clark's approach and draw upon our intuitive judgments regarding cognition (for arguments supporting this approach, see Clark, 2011).

Although the Otto and Inga example focuses on memory and dispositional belief, the 
parity principle is intended to apply to all cognitive processes, including perceptual processes. And, in fact, while they have not always been at the centre of the debate, a number of examples that we find in the literature involve extended perceptual processes. In Natural-Born Cyborgs (2003) for example, Clark discusses many cases in which, he argues, external devices become part of our perceptual apparatus. These include advanced cochlear implants (p. 16), augmented reality goggles (p. 46), telepresence technologies (p. 96), artificial vision systems (p. 124) and Tactile Visual Sensory Substitution (TVSS) (p. 125). In each of these cases, Clark suggests, the human perceptual system extends beyond the brain and body to incorporate external, non-biological devices. For example, an advanced cochlear implant consisting of an external, electronic speech processor and receiver unit wired under the scalp, along with wires connecting to the brain stem, might nevertheless become part of a person's auditory system (2003, p.16-17). In a similar vein, Chalmers suggests that smartphone cameras might in some cases serve as extended perceptual mechanisms (Chalmers, 2008, p. xiv). (Other discussions of the extended mind thesis and perception include Kiverstein and Farina (2012), Rowlands (1999, Chapter 5) and Wilson (2010).)

\section{Extended perception and empiricism}

The notion of extended perception allows the realist to formulate a new argument against the constructive empiricist view of instruments, which I will call the extended perception argument. Put simply, the argument claims that, under certain conditions, instruments may become part of the scientists' perceptual processes, just as Otto's notebook becomes part of his memory. As a result, the scientist literally perceives objects through this extended perceptual process, just as Otto literally believes things written in his notebook. And so, contra van Fraassen, objects detectable using these instruments should count as observable. The extended perception argument thus aims to support the realists' view that the development of new scientific instruments, like microscopes, has enabled us to observe new phenomena previously beyond the reach of our senses. According to the 
extended perception argument, when we peer into a microscope, we do see cells or microbes; we see them with an extended perceptual system that includes both our eyes and the microscope itself.

Put in more detail, the extended perception argument runs as follows:

1 Object $\mathrm{X}$ is detectable using instrument $\mathrm{Y}$ but not with the unaided senses

2 When used by the scientist, instrument $Y$ forms part of her perceptual processes

2.i (By intuitive judgment) If $\mathrm{Y}$ were inside the head of a Martian, it would count as part of the Martian's perceptual processes

2.ii (By the parity principle) Y is part of the scientist's perceptual processes

3 Therefore, contra van Fraassen, $\mathrm{X}$ is observable

The argument thus asks us to consider some object $\mathrm{X}$ that is detectable using a scientific instrument $Y$ but not with the naked eye (or ear, nose, etc.) (premise 1). Under certain circumstances, it is claimed, instrument $Y$ becomes part of the scientist's perceptual processes (premise 2). The support for this key premise in the argument is provided by the parity principle. First, it is argued that, if instrument $Y$ were found inside the head of a Martian, then we would have no hesitation in judging it to be part of the Martian's perceptual processes (premise 2.i). Next, by applying the parity principle, we see that, if $\mathrm{Y}$ is part of the Martian's perceptual processes, then it is also part of the scientist's perceptual processes (premise 2.ii). After all, by construction, the only difference between the two cases is whether the instrument happens to lie inside or outside the head. As a result, although it cannot be detected by the naked eye, object $\mathrm{X}$ is detectable through the scientist's (extended) perceptual system. Object X may, therefore, be perceived or observed by the scientist and so should count as observable.

To take an example, consider a light microscope. Microscopes have been the subject of considerable disagreement between the realist and constructive empiricist. For the realist, light microscopes allow us to see new objects hitherto invisible to us. For the constructive empiricist, on the other hand, we should suspend judgment on whether such entities exist 
and instead view the microscope as a machine for generating new phenomena. The extended perception argument now asks us to imagine a Martian with a mechanism inside its head that is equivalent to the human eye together with a light microscope. If we encountered such a being, it is argued, we would have no hesitation in saying that this mechanism was part of the Martian's perceptual processes. We would say that the Martian can see (or observe) cells, microbes, and so on. Therefore, by the parity principle, the microscope should count as part of the scientists' perceptual processes and cells and microbes should count as observable to the scientist as well. After all, the only difference between the Martian and the scientist is that, in the scientist's case, the microscope lies outside the skull.

Although the extended perception argument as I have just presented it relies upon the parity principle, in the literature we find many different considerations given in support of the extended mind thesis or related positions. For example, some authors appeal to the idea that individuals and external devices can sometimes be closely coupled in certain ways (e.g. Clark, 2010; Haugeland 1998). Other discussions appeal to the phenomenology of fluent tool use and the notion that external objects are sometimes incorporated into a person's body image (e.g. Clark, 2003). (A well-known example here, of course, is the blind person using a cane.) Each of these considerations might also be offered in support of the key premise in the extended perception argument (premise 2). Moreover, as we will see below, some of these considerations find echoes in existing realist arguments concerning instruments. Partly for this reason, however, I will focus mainly on the paritybased version of the argument that I introduced above. As we shall see, this form of the extended perception argument provides the realist with a new way to respond to the constructive empiricist view of instruments.

\section{Classic realist arguments}

At first glance, the extended perception argument bears a striking similarity to a number of well-known realist responses to empiricism, including arguments found in classic 
papers by Grover Maxwell and Paul Churchland. Both of these arguments also appeal to the possibility of beings with different perceptual systems. In fact, however, I want to argue that the extended perception argument differs from existing realist arguments in important respects. Because of this, I will also argue that the extended perception argument is able to avoid van Fraassen's responses to those earlier arguments.

\subsection{Maxwell}

Grover Maxwell's classic paper 'The Ontological Status of Theoretical Entities' (1962) mounts a number of different challenges to empiricism, and to the observableunobservable distinction in particular. One of Maxwell's arguments appeals to the possibility of beings with radically different sense organs. He asks us to 'suppose a human mutant is born who is able to "observe" ultraviolet radiation, or even X rays, in the same way we "observe" visible light' (1962, p. 11). Maxwell uses this possibility to challenge the notion that any object is unobservable in principle. After all, he argues, to say that an object is unobservable in principle is to say that it could not be observed under any circumstances. And yet it seems that no object will meet this criterion, since in different circumstances we might possess radically different sense organs, like those of the mutated human able to observe ultraviolet radiation or X-rays. Van Fraassen's response to Maxwell is simply to re-iterate that, for the constructive empiricist, 'observable' means 'observable-to-us'. In other words, to say that a phenomenon is observable is to say that it is observable to human beings with their own particular sensory apparatus. Because of this, van Fraassen argues, the constructive empiricist may safely dismiss Maxwell's thought experiment as irrelevant, since it tells us nothing about what is observable-to-us (that is, 'us' as non-mutated human beings).

Like Maxwell's challenge to the empiricist, the extended perception argument also appeals to the possibility of beings with radically different sense organs, namely Martians with microscope eyes (premise 2.i). However, via the parity principle, it then proceeds to argue that, if microscopes count as part of the alien's perceptual processes, then they 
should also count as part of the scientist's (premise 2.ii). The extended perception argument thus goes further than Maxwell, claiming that beings with microscope eyes are not only possible, but actual. Or, to put the point slightly differently, the argument claims that there are already people with radically different perceptual systems, like Maxwell's mutants. The only difference is that they gained these perceptual systems not through mutation, but by becoming cyborgs. That is, they have incorporated external devices into their cognitive system, just as Otto has incorporated his notebook into his cognitive system.

Along with other realists, Maxwell objects to the core empiricist claim that the limits of what can be known are determined by the limitations of human perceptual capacities. In contrast, as we saw in Section 2, the extended perception argument can concede this point to the empiricist. Rather than rejecting the empiricist's claim that our knowledge is limited by our perceptual capacities, the extended perception argument challenges the assumption that human perceptual capacities are limited to the capacities of the naked eye, ear and so on. Instead, it argues, human perceptual processes can sometimes include external, material devices, like scientific instruments. Van Fraassen has often conceded that realists will find constructive empiricism too anthropocentric, placing too great an emphasis on the contingent limitations of the human organism. From the point of view of the extended perception argument, however, what constructive empiricism is guilty of is not anthropocentricism but 'skull-centricism': it wrongly assumes that the limits of the human perceptual system are bound by the skull. If, instead, humans are indeed 'naturalborn cyborgs', then our perceptual system is more open and plastic than van Fraassen allows.

\subsection{Churchland}

The extended perception argument is also reminiscent of a famous thought experiment due to Paul Churchland:

[s]uppose a race of humanoid creatures each of whom is born with an 
electron microscope permanently in place over his left 'eye'. The scope is biologically constituted, let us suppose, and it projects its image onto a human-style retina, with the rest of their neurophysiology paralleling our own.

Science tells us [...] that virus particles [and] DNA strands [...] count as observable entities for the humanoids described. The humanoids, at least, would be justified in so regarding them and in including them in their ontology.

But we humans may not include such entities in our ontology, according to van Fraassen's position, since they are not observable with our unaided perceptual apparatus. We may not include such entities in our ontology even though we can construct and even if we do construct electron microscopes of identical function, place them over our left eyes, and enjoy exactly the same microexperience as the humanoids.

The difficulty for van Fraassen's position [...] is that [it] requires that a humanoid and a scope-equipped human must embrace different epistemic attitudes toward the microworld, even though their causal connections to the world and their continuing experience of it be identical [...]. (1985, p. 4344)

Churchland thus accuses van Fraassen of endorsing unmotivated epistemic double standards: the constructive empiricist asks us to treat the humanoid and scope-equipped human differently, even though in all relevant respects the two cases are the same. Van Fraassen's response is that Churchland's thought experiment, although initially persuasive, in fact conflates two different scenarios (Van Fraassen, 1985, p. 256-266). In the first scenario, we meet the humanoids that Churchland imagines and we decide to accept them as persons, welcoming them into our epistemic community. Once this has happened, "we have already broadened the extension of $u s$, and what is observable to them is observable" (Van Fraassen, 1985, p. 256). In this scenario, van Fraassen argues, 
the constructive empiricist is not guilty of adopting any double standards since the boundaries of the observable have now widened as a result of the change to the epistemic community. In the second scenario, we choose not to count the humanoids as persons, and so the boundaries of the observable remain unaltered. But then, as van Fraassen points out, under this scenario, to assume that the humanoids have the same causal connections to the world as the scope-equipped human is simply to beg the question in favour of realism (1985, p. 256). (For a helpful discussion of the debate between Churchland and van Fraassen, see Dicken (2010).)

Once again, I want to suggest that, despite the obvious similarities between Churchland's thought experiment and the extended perception argument, there are important differences between the two. Churchland invokes the possibility of humanoids with microscope eyes in order to pose the question: why should it matter whether the microscope is part of the perceptual system (as it is in the humanoid's case) or outside the perceptual system (as in the case of the scope-equipped scientist)? By contrast, the extended perception argument claims that the microscope is part of the scientist's perceptual system, just as it is in humanoid's case. The point of the Martian thought experiment is simply to free us from our skin-and-skull prejudices and allow us to recognize this fact. Rather than conflating the two scenarios distinguished by van Fraassen, the extended perception argument in effect argues that the first scenario has already happened (or at least should already have happened). We have already encountered humanoids (or, more accurately, cyborgs) whose perceptual systems include microscopes and other scientific instruments, and we have (or should have) counted them as part of our epistemic community. The only reason that we haven't noticed these beings amongst us is that, unlike Churchland's humanoids, the cyborgs' perceptual systems extend outside their skulls. According to the extended perception argument, then, rather than being guilty of epistemic double standards, van Fraassen is guilty of an irrational 'cyborg-phobia', which leads him to overlook certain members of our epistemic community (namely, those who perceptual systems extend outside their bodies). 


\section{Prospects and problems}

Despite first appearances, then, the extended perception argument differs in important respects from Maxwell and Churchland's well-known challenges to empiricism, allowing it to avoid van Fraassen's responses to their arguments. In this section, I will suggest that the extended perception argument has a number of further advantages over alternative realist strategies for challenging the constructive empiricist view of instruments. I will also consider ways in which empiricists might respond.

One advantage of the extended perception argument is that it does not rely on an inference to the best explanation. In his famous paper, "Do we see through a microscope?" (1985), Ian Hacking offers a range of different arguments intended to justify our faith in microscopic observation. As critics have been quick to point out, however, a number of Hacking's arguments appear to rely upon inference to the best explanation. For example, Hacking points to the fact that we often see similar images when we look at a specimen through different sorts of microscopes, such as an electron microscope and fluorescence microscope, which each rely on different physical processes. For Hacking, this provides compelling evidence for the reality of the structures that we appear to see:

It would be a preposterous coincidence if, time and again, two completely different physical processes produced identical visual configurations which were, however, artefacts of the physical processes rather than real structures in the cell (1985, pp. 144-145).

The difficulty with this argument is that, despite Hacking's claims to the contrary (1985, pp. 145-146), it would seem to rely on an abductive inference: we are supposed to infer that the structures in the cell are real, since this would provide the best explanation for the similarities in the images that we see. And yet one of the central features of van Fraassen's position is his rejection of inference to the best explanation (see especially Van Fraassen, 1989). As a result, Hacking's arguments concerning microscopes, however 
compelling, threaten simply to return us to a more general ground of disagreement between realists and constructive empiricists (Alspector-Kelly, 2004). By contrast, the extended perception argument as I have presented it depends upon our intuitive judgment of whether a given process counts as perceptual, together with the parity principle's demand that such judgments should not depend upon the boundaries of the skin and skull. Neither move seems to rely upon inference to the best explanation. As a result, we do not find ourselves thrown back into the general debate over the reliability of this form of inference.

A further advantage of the extended perception argument is that it does not appeal to the phenomenology of instrument use. Some realists have sought to argue in this way. For example, Paul Teller has observed that, when the experienced microscopist looks into a microscope, she feels that she is observing cells and microbes directly, not any intermediate image (Teller, 2001, pp. 132-134). Given the compelling sense that we are looking directly at something real when we look through the microscope, why should we resist? (Alspector-Kelly, 2004, p. 336). In response to this line of argument, van Fraassen questions whether how things seem to us is a reliable guide to what is really happening (Van Fraassen, 2001, p. 155-160; 2008, p.105-109). After all, might we not be mistaken? Perhaps our experience when we peer into the microscope is an illusion, rather like seeing a rainbow (albeit a more convincing illusion). As we noted in Section 3, some arguments for the extended mind thesis also appeal to the phenomenology of tool use. A blind person using a cane, it is often said, does not feel the stick in her hand, but rather feels as if the cane were part of her body and she were touching the pavement directly. The form of the extended perception argument that I presented in Section 4, however, relies not upon the phenomenology of instrument use but upon the parity principle. The argument does not take the scientist's experience to indicate whether she is seeing an object or not; what matters is the process leading to her experience. As a result, the extended perception argument is not vulnerable to van Fraassen's response to arguments from the phenomenology of instrument use.

Despite its strengths, the extended perception argument might also be challenged in 
various ways. One obvious objection, of course, is that the extended mind thesis itself is hardly universally accepted. The continuing debate over the extended mind thesis is complex and I cannot hope to settle it here. In what follows, then, I will set aside this more general debate and focus upon criticisms specific to the extended perception argument. (For a useful overview of the debate over the extended mind thesis, see Menary, 2010.)

One way for the constructive empiricist to challenge the extended perception argument would be to reject the realist's claim that, if a Martian were to have, say, microscope eyes, then the processes involved would count as part of its perceptual processes (premise 2.i). The empiricist might seek to motivate this objection by noting that microscopes rely upon different physical processes to those involved in ordinary vision. Ian Hacking observes that, when we use an ordinary microscope, 'we synthesize diffracted rays rather than seeing the specimen by way of "normal" visual physics' (1985, p. 143). Other types of microscopes involve even more complex processes. The polarizing microscope uses polarizers and analyzers to allow us to detect transparent structures that we do not normally see. The phase contrast microscope allows us to detect differences in refractive index in different parts of specimen by converting them into visible differences of intensity (see Hacking, 1985, pp. 142-143). Given these differences between the processes involved in ordinary vision and those employed by microscopes, the constructive empiricist might ask whether Martians incorporating such devices should be really said to see cells or microbes.

Notice, however, that the extended perception argument does not rely on the claim that the aliens perceive objects using the same physical processes, or even with the same finegrained perceptual psychology, as we do. In fact, the realist need not even insist that the Martian would be able to see cells or microbes. Instead, all that matters is that we would count the Martian's microscope eyes as part of a perceptual process of some sort, so that the Martian may be said to perceive cells, microbes and so on, and such entities count as observable for them. As far as I am aware, nobody in the debate over realism and instruments challenges this claim. Certainly, van Fraassen himself does not object to 
Churchland's assumption that the humanoids in his thought experiment would be able to perceive atoms; his complaint lies rather with the implications that Churchland draws from this.

Another way to challenge the extended perception argument would be to argue that, even if cases of instrument use meet the demands of the parity principle, they fail to meet some other relevant criteria for extended cognition. In their original paper, Clark and Chalmers suggest that, in order to count as part of the cognitive process, an external device must meet what Clark refers to as conditions of "glue and trust" (Clark, 2010). These conditions require that, like Otto's notebook, an external process must be a constant in the person's life, directly available and automatically endorsed (Clark and Chalmers, 1998, p. 17). An opponent of the extended perception argument might object that these conditions are not met in typical cases of instrument use. For example, a scientist might not always have access to her microscope and she might sometimes question whether it is working properly.

There are a number of ways in which the realist might respond to this objection. First, she might argue that the glue and trust conditions are met in (at least some) cases of instrument use. Perhaps for the experienced microscopist, routinely inspecting specimens each day, her microscope is a constant in her life, directly available to her and automatically endorsed. Second, the realist might reject the glue and trust conditions themselves. Clark and Chalmers formulate these conditions by reflecting on a case of extended belief, namely Otto and his notebook. But it is far from clear that they need apply to all forms of cognitive extension. For example, Wilson and Clark (2009, p. 66-68) suggest that cases in which glue and trust conditions are met (like Otto) form only a subset of a much wider set of cases of cognitive extension, which includes more transient systems (formed when we reach for pen and paper while trying to solve a crossword anagram, for example).

What about cases of extended perception? Must the glue and trust conditions be met here? Arguably not. Consider once more our Martian with a microscope mechanism lodged inside his head. Now suppose that the Martian is only able to make use of this mechanism 
for at certain times (perhaps when he is not too tired, say, or has had a good meal). At other times, let us imagine, his vision is much like ours. Furthermore, suppose that the Martian is sometimes rather cautious about the deliverances of his microscope eye and questions whether it might, on occasion, mislead him). Despite these further complications, it seems to me that we would still say that, when the Martian is using his microscope mechanism, the processes that take place in it form part of his perceptual processes. The Martian would still be able to perceive cells, microbes and so on, notwithstanding the effort required to use his special ability and his cautious attitude towards it (for similar considerations, put to rather different use, see Sprevak, 2009). (Of course, one worry about dropping the glue and trust conditions is that we might be left with an overly-permissive expansion of the cognitive (see also Sprevak, 2009).)

A final way in which the empiricist might challenge the extended perception argument focuses not on the idea of the extended mind, but on the (closely related) notion of the extended person. In Section 5(ii), we saw that, unlike Churchland's thought experiment, the extended perception argument claims that our epistemic community already contains beings whose perceptual processes enable them to perceive cells and microbes. We have merely overlooked this fact, since their perceptual systems extend into the environment. The empiricist might object that this is a little too quick, however. Although it is certainly true to say that we are happy to admit people who wear glasses and use microscopes, into our epistemic community, the extended perception argument in fact relies on a rather different claim. That is the claim that we have admitted (or should admit) extended persons into our epistemic community, that is, persons whose perceptual system extends into the environment to incorporate glasses, microscopes, and so on.

Although the notion of extended persons is perhaps a strange one, it is not an idea that we may simply dismiss out of hand. In fact, a number of defenders of the extended mind thesis have argued for the notion of extended persons (or an extended self). For example, near the end of their paper, Clark and Chalmers write:

Does the extended mind imply an extended self? It seems so. [...] The information in Otto's notebook [...] is a central part of his identity as a 
cognitive agent. What this comes to is that Otto himself is best regarded as an extended system, a coupling of biological organism and external resources. (1998, p.18)

Such judgments, Clark and Chalmers argue, will have moral and social dimensions. For example, 'It may be [...] that in some cases interfering with someone's environment will have the same moral significance as interfering with their person' (Clark and Chalmers, 1998, p. 18).

What about those with extended perceptual systems? Should they be recognized as persons and admitted into our epistemic community? At a number of points, van Fraassen considers the possibility that the make-up of our epistemic community might change. For example, in The Scientific Image, he writes that

At present, we count the human race as the epistemic community to which we belong; but this race may mutate, or that community may be increased by adding other animals (terrestrial or extra-terrestrial) through relevant ideological or moral decisions ('to count them as persons'). (1980, p. 18)

But van Fraassen says little more about how exactly we should make such judgments. In the absence of more explicit criteria for membership of the epistemic community, it is difficult to see how the constructive empiricist may exclude the possibility that it should contain those with extended perceptual systems. Instead, it seems that deciding such questions is likely to turn on more general issues concerning personhood. Such issues cannot be decided here. But it is, I think, one of the more interesting consequences of the extended perception argument that the outcome of the debate between realists and constructive empiricists might turn out to depend upon answers to questions concerning personhood and the proper bounds of the epistemic community. 


\section{Conclusion}

In this paper, I have considered whether the scientific realists' conception of instruments as extensions to our perceptual capacities can be fleshed out by drawing on the extended mind thesis. I have argued that it can. In fact, the extended mind thesis allows realists to pose a new challenge to the constructive empiricist view of instruments, which I have called the extended perception argument. I have tried to show how this argument differs from classic realist arguments against empiricism in a number of important respects, and how these differences allow it to avoid van Fraassen's responses to those arguments. Even if it is successful, the extended perception argument need not lead us to reject the core claim of constructive empiricism, that we should restrict our belief to what science tells us about the observable phenomena. But the argument does challenge the constructive empiricist's claim that the bounds of the observable are fixed by the limits of the biological senses. Instead, we are left with an empiricism for cyborgs, in which scientists' perceptual processes sometimes extend beyond skin and skull and the bounds of the observable far exceed those of the naked eye.

\section{Acknowledgements}

I would like to thank Giovanna Colombetti, Joel Krueger, Orestis Palermos, Tom Roberts, Karola Stotz and Elena Walsh for helpful comments on a draft of this paper, as well as the audience at the annual conference of the British Society for the Philosophy of Science at the University of Exeter, July $4-5^{\text {th }} 2013$. This project has received funding from the European Union's Seventh Framework Programme for research, technological development and demonstration under grant agreement no. 331432. 


\section{References}

Adams, F., \& Aizawa, K. (2001). The bounds of cognition. Philosophical Psychology, 14(1), 43-64.

Alspector-Kelly, M. (2004). Seeing the Unobservable: Van Fraassen and the Limits of Experience. Synthese, 140(3), 331-353.

Churchland, P. (1985). The Ontological Status of Observables: In Praise of the Superempirical Virtues. In P. M. Churchland \& C. A. Hooker (Eds.), Images of Science: Essays on Realism and Empiricism, with a Reply from Bas C. van Fraassen (pp. 35-47). Chicago: University of Chicago Press.

Clark, A. (2003). Natural-Born Cyborgs: Minds, Technologies, and the Future of Human Intelligence. Oxford: Oxford University Press.

Clark, A. (2008). Supersizing the mind. Oxford: Oxford University Press.

Clark, A. (2011). Finding the Mind. Philosophical Studies, 152(3), 447-461.

Clark, A. \& Chalmers, D. (1998). The Extended Mind. Analysis, 58(1), 7-19.

Clark, A., Pritchard, D. \& Vaesen, K. (Eds.). (2012). Extended cognition and epistemology [Special issue]. Philosophical Explorations, 15(2).

Dicken, P. (2010). Constructive Empiricism: Epistemology and the Philosophy of Science. Basingstoke: Palgrave Macmillan.

Estany, A. \& Sturm, T. (Eds.) (2014). The extended cognition thesis: Its significance for the philosophy of (cognitive) science [Special issue]. Philosophical Psychology, 27(1).

Hacking, I. (1981/1985). Do We See Through a Microscope? In P. M. Churchland \& C. A. Hooker (Eds.), Images of Science: Essays on Realism and Empiricism, with a Reply from Bas C. van Fraassen (pp. 132-162). First published in Pacific Philosophical Quarterly, 62, 305-322 (1981). 
Haugeland, J. (1998). Mind embodied and embedded. In his Having Thought: Essays in the Metaphysics of Mind. Cambridge, MA: Havard University Press.

Humphreys, P. (2004). Extending Ourselves: Computational Science, Empiricism and Scientific Method. Oxford: Oxford University Press.

Kiverstein, J. \& Farina, M. (2012). Do sensory substitution devices extend the conscious mind? In F. Paglieri (Ed.) Consciousness in Interaction: The role of the natural and social context in shaping consciousness. Amsterdam: John Benjamins Publishing Co.

Kusch, M. (2013). Microscopes and the Theory-Ladenness of Experience in Bas van Fraassen's Recent Work. Unpublished manuscript retrieved from http://www.academia.edu/2542922/Microscopes_and_the_Theory-

Ladenness_of_Experience_in_Bas_van_Fraassens_Recent_Work

Maxwell, G. (1962). The Ontological Status of Theoretical Entities. In H. Feigel \& G. Maxwell (Eds.), Minnesota studies in the philosophy of science, Vol. III (pp. 3-27).

Menary, R. (2007). Cognitive integration: mind and cognition unbounded. Basingstoke: Palgrave Macmillan.

Menary, R. (Ed.) (2010). The Extended Mind. Cambridge, MA: MIT Press.

Pritchard, D. (2010). Cognitive ability and the extended cognition thesis. Synthese, 175(1), 133-151.

Robbins, P., \& Aydede, M. (Eds.). (2009). The Cambridge handbook of situated cognition. Cambridge: Cambridge University Press.

Rupert, R. D. (2004). Challenges to the Hypothesis of Extended Cognition. The Journal of Philosophy, 101(8), 389-428.

Sprevak, M. (2009). Extended Cognition and Functionalism. The Journal of Philosophy, 106(9).

Vaesen, K. (2011). Knowledge without credit, exhibit 4: extended cognition. Synthese, 181(3), 515-529. 
Van Fraassen, B. C. (1980). The Scientific Image. Oxford University Press.

Van Fraassen, B. C. (1985). Empiricism in the Philosophy of Science. In P. M.

Churchland \& C. A. Hooker (Eds.), Images of Science: Essays on Realism and

Empiricism, with a Reply from Bas C. van Fraassen (pp. 245 - 308). University of Chicago Press.

Van Fraassen, B. C. (1989). Laws and Symmetry. Oxford University Press.

Van Fraassen, B. C. (2001). Constructive Empiricism Now. Philosophical Studies, 106(1/2), 151-170.

Van Fraassen, B. C. (2008). Scientific Representation: Paradoxes of Perspective. Oxford University Press.

Wheeler, M. (2005). Reconstructing the Cognitive World. Cambridge, MA: MIT Press.

Wheeler, M. (2011). In search of clarity about parity. Philosophical Studies, 152(3), 417425. 